(c) American Dairy Science Association, 2006.

\title{
Journal of Dairy Science 2005 Editorial Report
}

\author{
Gary W. Rogers, Editor-in-Chief \\ Department of Animal Science, University of Tennessee, Knoxville, 37996
}

I bring you greetings on behalf of the editors for the Journal of Dairy Science (JDS). Thanks to Dr. Steve Nickerson from the University of Georgia for serving as Editor-in-Chief for JDS until the end of 2005. Dr. Nickerson has provided outstanding leadership to JDS and he witnessed an unequalled growth in JDS. Dr. Nickerson should be very pleased with the position and performance of JDS at the end of his term and at his departure from the position of Editor-in-Chief. At the end of 2005, JDS reached a new level of performance and position, and JDS is approaching 90 years of successful publication. Thanks also to the staff members at ADSA headquarters who make the job of Senior Editors, Section Editors, and the Editor-in-Chief much easier than it would be without their contributions. The staff members that work on JDS are extremely efficient and very professional in their work. I would especially like to acknowledge the efforts of Susan Pollock, the Managing Editor of JDS and FASS Director of Editorial and Production, and Louise Adam, the Technical Editor of JDS and Assistant Director of Editorial and Production. Jeremy Holzner should be recognized for his contributions to the publication process as he coordinates the efforts on Manuscript Central; Sharon Frick should be recognized for her excellent work in the layout and production of JDS. These and other FASS staff members working on JDS are extremely efficient, and they are the reason that JDS has seen significant improvements in publication turnaround times in recent months. We should all show our appreciation to their work when given the opportunity. The overall leadership of ADSA by Brenda Carlson has been outstanding as well. Brenda has strongly supported JDS during her years as Executive Director and JDS would not have reached its current level without her unwavering support.

The Journal of Dairy Science continues to be one of the preeminent scientific journals serving the needs of dairy scientists from around the world. The impact factor from the most recent Institute for Scientific Information indicates that JDS is surpassed in impact factor by only 2 specialized journals in the category of agriculture, dairy, and animal science, which comprises 41 major journals. The impact factor is based primarily on journal citation reports and is an excellent measure of journal quality and the level of journal recognition. The impact factor for JDS is 2.13 , which is higher than all other scientific journals in the agriculture, dairy, and animal science category except Animal Genetics and Domestic Animal Endocrinology. In addition, the good news for our Dairy Foods section is that JDS also ranks very high among food science and technology journals. Out of 91 journals in the food science and technology category, JDS ranks 8th in impact factor. This ranking is outstanding, especially given that JDS publishes a variety of papers outside the Dairy Foods section and focused food science and technology journals tend to have very high impact factors. The outstanding impact factor for JDS is a testament to the outstanding work of the authors, reviewers, editors, and staff who work on JDS.

Recent enhancements to JDS include the posting of online-only publications from symposia so that they are now searchable by major search engines. These onlineonly articles from symposia are now searchable just like traditional articles in JDS. In addition, JDS articles from January 1990 are now available on HighWire (http://jds.fass.org/).

In 2005, JDS published 474 articles and 4,451 pages (Tables 1 and 2). This is the third consecutive year in which JDS has published more than 400 manuscripts and more than 4,000 pages. The number of papers in 2005 was similar to that in 2004, but 2004 was an aberration, because the journal published several backlogged papers from 2003. In 2005, JDS published 435 research papers, 29 papers in the Our Industry Today (OIT) section, and 3 invited reviews. In addition, JDS also published 3 symposium papers in the online-only version, which was down from 13 symposium papers published in 2004.

The largest section in JDS in 2005 was the Nutrition, Feeding, and Calves section with 136 research papers (Table 3). The second largest section was the Physiology and Management section with 116 research papers. The Dairy Foods and Genetics and Breeding sections published 101 and 82 research papers, respectively. The Physiology and Management section also published 19 OIT papers and the Nutrition, Feeding, and Calves section published 7 OIT papers. Of the article types other than full-length research papers or OIT papers, Short Communications were most frequent. In 2005, JDS published 20 Short Communications, 3 Invited Re- 
Table 1. Journal of Dairy Science statistics for 2005 compared with previous years

\begin{tabular}{lrrrrrrrr}
\hline & 2005 & 2004 & 2003 & 2002 & 2001 & 2000 & 1999 & 1998 \\
\hline Avg. papers received/mo & 76 & 65 & 56 & 53 & 50 & 44 & 42 & 39 \\
Avg. papers accepted/mo & 42 & 39 & 38 & 37 & 31 & 30 & 28 & 26 \\
Avg. papers published/mo & 40 & 40 & 38 & 33 & 30 & 29 & 28 & 33 \\
Pages published & 4,451 & 4,562 & 4,341 & 3,633 & 3,091 & 3,413 & 2,944 & 3,541 \\
Average review time (d) & 122 & 132 & 105 & 121 & 158 & 158 & 180 & 204 \\
Average production time (d) & 92 & 135 & 151 & 159 & 125 & 137 & 115 & 143 \\
Average total time (d) & 214 & 267 & 256 & 280 & 283 & 295 & 295 & 347 \\
\hline
\end{tabular}

views, 3 Technical Notes, 1 Hot Topic paper, and 4 Letters to the Editor.

The total time from receipt of a manuscript until final publication in JDS continues to be outstanding. In 2005, the average time in review for accepted papers was 122 days and the average time from acceptance until the papers were ready for posting and printing was down to 82 days! This quick turn-around on accepted papers is the result of extremely efficient editorial and production staff. It takes about 10 more days to get the issue posted online and mailed to subscribers, so total average production time after acceptance was 92 days. The average total time from submission to publication for an accepted paper was 214 days in 2005 . A few papers (where reviewers were unresponsive or authors were slow to respond) skew this number somewhat so most accepted papers required fewer than 200 days from submission to publication.

Another important statistic for JDS is the time that it takes to get the first decision on a paper. The average time from submission to the first decision is now below 45 days; this reflects good work on the part of most reviewers. The average time from submission to reviewer assignment is less than 3 days. Many papers will have an initial decision within 3 weeks after submission and some of the very best papers will be accepted within
3 weeks after submission. Papers that require multiple revisions can still take several months before a final decision. Overall, the Senior Editors, Section Editors, and reviewers have done an outstanding job in 2005 .

The rate of new submissions to JDS continues to increase. In 2005, JDS had 908 new manuscripts submitted for consideration. In addition, JDS had 836 revised manuscripts submitted in 2005 . The total number of manuscripts handled by our Senior Editors and Section Editors in 2005 was 1,744! This is a large number of papers to handle in one year and it bodes well for a strong JDS in the near future. The latest data on the acceptance rate of submitted papers indicate that JDS accepts about 55 to $60 \%$ of the manuscripts that are submitted. The exact acceptance rate depends on the time window chosen, how papers that are immediately rejected for missing components are handled, and how withdrawn papers are handled. Many papers require at least one revision before acceptance.

Retiring Senior Editors and Section Editors from 2005 include S. P. Washburn (Physiology and Management) and R. A. Kohn (Nutrition, Feeding, and Calves). The current editors would like to give a special thanks to the 2 retiring editors. They have worked very hard for JDS over the past several years. New Section Editors for JDS include Frank Gwazdauskas (Physiology

Table 2. Journal of Dairy Science manuscript and page statistics by article type for 2005

\begin{tabular}{|c|c|c|c|c|c|c|c|c|}
\hline \multirow[b]{2}{*}{ Month } & \multicolumn{2}{|c|}{ Research } & \multicolumn{2}{|c|}{$\begin{array}{c}\text { Our Industry } \\
\text { Today }\end{array}$} & \multicolumn{2}{|c|}{ Invited Review } & \multicolumn{2}{|c|}{ Symposium } \\
\hline & Papers & Pages & Papers & Pages & Papers & Pages & Papers & Pages \\
\hline January & 45 & 398 & 5 & 34 & 0 & 0 & 0 & 0 \\
\hline February & 42 & 376 & 0 & 0 & 1 & 16 & 0 & 0 \\
\hline March & 39 & 374 & 4 & 46 & 1 & 14 & 0 & 0 \\
\hline April & 34 & 313 & 2 & 18 & 0 & 0 & 0 & 0 \\
\hline May & 32 & 273 & 3 & 26 & 0 & 0 & 0 & 0 \\
\hline June & 35 & 342 & 2 & 18 & 0 & 0 & 0 & 0 \\
\hline July & 36 & 365 & 2 & 21 & 1 & 6 & 0 & 0 \\
\hline August & 33 & 308 & 4 & 45 & 0 & 0 & 0 & 0 \\
\hline September & 35 & 317 & 2 & 22 & 0 & 0 & 0 & 0 \\
\hline October & 35 & 323 & 3 & 34 & 0 & 0 & 0 & 0 \\
\hline November & 37 & 383 & 1 & 12 & 0 & 0 & 0 & 0 \\
\hline December & 32 & 304 & 1 & 11 & 0 & 0 & 0 & 0 \\
\hline E. Supplement & 0 & 0 & 0 & 0 & 0 & 0 & 3 & 37 \\
\hline Total & 435 & 4,076 & 29 & 287 & 3 & 36 & 3 & 37 \\
\hline
\end{tabular}


Table 3. Journal of Dairy Science research manuscripts and page statistics by science section ${ }^{1}$ for 2005

\begin{tabular}{|c|c|c|c|c|c|c|c|c|}
\hline \multirow[b]{2}{*}{ Month } & \multicolumn{2}{|c|}{$\mathrm{DF}$} & \multicolumn{2}{|c|}{ PM } & \multicolumn{2}{|c|}{$\mathrm{NFC}$} & \multicolumn{2}{|c|}{ GB } \\
\hline & Papers & Pages & Papers & Pages & Papers & Pages & Papers & Pages \\
\hline January & 8 & 66 & 17 & 156 & 12 & 104 & 8 & 72 \\
\hline February & 8 & 68 & 11 & 91 & 15 & 151 & 8 & 66 \\
\hline March & 7 & 57 & 9 & 80 & 13 & 148 & 10 & 89 \\
\hline April & 9 & 87 & 4 & 35 & 10 & 86 & 11 & 105 \\
\hline May & 7 & 67 & 8 & 60 & 12 & 110 & 5 & 36 \\
\hline June & 6 & 59 & 5 & 41 & 14 & 151 & 10 & 91 \\
\hline July & 7 & 66 & 12 & 126 & 12 & 129 & 5 & 44 \\
\hline August & 3 & 24 & 12 & 106 & 14 & 136 & 4 & 42 \\
\hline September & 12 & 102 & 9 & 81 & 4 & 45 & 10 & 89 \\
\hline October & 12 & 111 & 7 & 65 & 11 & 102 & 5 & 45 \\
\hline November & 11 & 114 & 12 & 112 & 10 & 120 & 4 & 37 \\
\hline December & 11 & 102 & 10 & 95 & 9 & 92 & 2 & 15 \\
\hline Total & 101 & 923 & 116 & 1,048 & 136 & 1,374 & 82 & 731 \\
\hline
\end{tabular}

${ }^{1} \mathrm{DF}$ = Dairy Foods; PM = Physiology and Management; NFC = Nutrition, Feeding, and Calves; and GB = Genetics and Breeding. Table does not include Our Industry Today manuscripts, invited reviews, or symposium papers.

and Management), James Spain (Nutrition, Feeding, and Calves), and Filippo Miglior (Genetics and Breeding). These 3 new Section Editors are already working at full speed in their new positions.

The Senior Editors, Section Editors, and Editor-inChief would like to express their gratitude to the JDS Editorial Board and the very large number of ad hoc reviewers for their service to JDS. The timely and dedicated effort provided by the Editorial Board and the ad hoc reviewers is essential to maintaining the reputation of JDS and the efforts of these reviewers are greatly appreciated.
The current Journal Management Committee (JMC) is chaired by Rafael Jimenez-Flores. Other members of the JMC are Ric Grummer, Pete Hansen, MaryAnne Drake, John Bernard, and John Lucey. Please let one of the JMC members or one of the editors know if you have concerns that JDS should address.

If the 2005 volume of JDS is a good indicator of future JDS volumes, then the journal is positioned well for the future. A strong JDS is critical to the future success of the American Dairy Science Association, our dairy industries, and the professionals who contribute to JDS. Best wishes to all authors, reviewers, editors, and readers for a successful 2006 . 